\title{
Resenha: "Políticas Públicas: conceitos, esquemas de análise, casos práticos", de Leonardo Secchi
}

\section{Informações editoriais:}

Autor: Leonardo Secchi

Editora: Cengage Learning

Cidade: São Paulo

Ano: 2014

ISBN 978-8522113538

\author{
Alberto Abad \\ Mestrando em Estudos de Fronteira PPGEF-UNIFAP. Professor de Psicologia na Universidade \\ CUT (México) e Universidad del Desarrollo Profesional (México). \\ E-mail alpabad@hotmail.com
}

O livro "Políticas Públicas: conceitos, esquemas de análise, casos práticos” (2014) de autoria do Doutor Leonardo Secchi, atual Pró-Reitor de Planejamento e Professor da Universidade do Estado de Santa Catarina, tem como objetivo introduzir de forma didática o tema das Políticas Públicas. Trata-se de um texto que pode ser utilizado tanto por aqueles que estão iniciando na área das Políticas Públicas, quanto por aqueles que desejam aprofundar o tema. Nesse sentido, o autor utiliza uma linguagem simples e direta, acrescentando ao final da obra, um glossário de termos como complemento à leitura.

O texto está organizado em torno de cinco dimensões das políticas públicas: de conteúdo (tipos de política pública); temporal (ciclos de políticas públicas); espacial (instituições); de atores; e comportamental (estilos de políticas públicas). Cada capítulo é concluído com um mini caso que aprofunda e fixa o tema desenvolvido pelo autor.

No prefácio, o autor salienta que a área de políticas públicas "consolidou, nos últimos sessenta anos, um corpus teórico próprio, um instrumental analítico útil e um vocabulário voltado para a compreensão de fenômenos de natureza político-administrativa”, e considera, que “[...] as 
ABAD, Alberto. "Políticas Públicas: conceitos, esquemas de análise, casos práticos", de Leonardo Secchi

policy sciences nasceram para ajudar no diagnóstico e no tratamento de problemas públicos” (prefacio XIII).

Na introdução o autor, de forma didática, analisa e define os principais termos que facilitam a compreensão do tema das políticas públicas; vocábulos indispensáveis para um ótimo entendimento dos capítulos a seguir. Assim sendo, inicia com o conceito de “política” e suas variantes na língua inglesa: desta forma, uma política pública “é uma diretriz elaborada para enfrentar um problema público [e] possui dois elementos fundamentais: intencionalidade pública e resposta a um problema público” (SECCHI, 2014, p. 1).

Secchi (2014) considera que existem duas abordagens de estudos de políticas públicas: a estatista, (state centered policy-making) que “considera as políticas públicas, analiticamente, monopólio de atores estatais” e a abordagem multicêntrica, que “considera organizações privadas, organizações não governamentais, organismos multilaterais, redes de políticas públicas (policy networks), juntamente com os atores estatais, protagonistas no estabelecimento das políticas públicas” (SECCHI, 2014, p. 2).

O autor, no intuito de definir a abordagem que aplicará no livro, menciona que considerará:

[...] a abordagem multicêntrica [...] porque adota um enfoque mais interpretativo e, por consequência, menos positivista, do que seja a política pública [...] segundo, porque evitamos uma pré-análise de personalidade jurídica de uma organização antes de enquadrar suas políticas como sendo públicas [...] terceiro, porque essa abordagem tem implicação em um espectro grande de fenômenos [...] quarto, porque o papel do Estado varia em cada país, e muda constantemente dentro de um mesmo país (SECCHI, 2014, p. 3).

O segundo capítulo aborda a dimensão de conteúdo, que trata dos tipos de políticas públicas. O autor comenta que "a ciência política tradicional sempre encarou as policies como um resultado das dinâmicas de enfrentamento, disputa de poder e resolução de interesses”.1 (SECCHI, 2014, p. 8).

1 David Easton (1953) entendia as políticas públicas como um produto do processo político que transforma inputs (demandas e apoios) em outputs (decisões e ações).

Revista Brasileira de Políticas Públicas e Internacionais, v.2, n.2, Dezembro/2017, pp. 168-175. 
ABAD, Alberto. "Políticas Públicas: conceitos, esquemas de análise, casos práticos", de Leonardo Secchi

O autor apresenta diferentes tipologias, sendo a primeira a elaborada por Lowi, que considera o critério de “impacto esperado na sociedade” (LOWI, 1964, apud SECCHI, 2014, p. 16), segundo o qual existem quatro tipos de políticas públicas:

Políticas regulatórias; estabelecem padrões de comportamento, serviço ou produto para atores públicos ou privados [...] Políticas distributivas; geram benefícios concentrados para alguns grupos de atores e custos difusos para toda a coletividade/contribuintes [...] Políticas redistributivas; concedem benefícios concentrados a algumas categorias de atores e implicam custos concentrados sobre outras categorias de atores [...] representa um jogo de soma zero [...] Políticas constitutivas; são regras sobre os poderes e regras sobre as regras (LOWI, 1985, p. 74), ou seja, são aquelas políticas que definem as competências, jurisdições, regras da disputa política e da elaboração de políticas públicas. São chamadas metapolicies porque se encontram acima dos outros três tipos de políticas e comumente moldam a dinâmica política nessas outras arenas (SECCHI, 2014, p. 18).

Outra tipologia apontada por Secchi (2014), refere-se à de James Quinn Wilson que “formulou sua tipologia adotando o critério da distribuição dos custos e benefícios da política pública na sociedade. Essa tipologia de um lado, corrobora a tipologia de Lowi, e de outro, a complementa”. (SECCHI, 2014, p. 19). Assim, considera:

As políticas de tipo clientelista [que] são aquelas em que os benefícios são concentrados em certos grupos e os custos são difusos na coletividade. São as políticas distributivas da tipologia de Lowi [...] as políticas de grupo de interesses, são aquelas em que tanto, custos como benefícios estão concentrados sobre certas categorias. Referem-se na tipologia de Lowi, às políticas redistributivas. [...] as políticas empreendedoras, importam em benefícios coletivos, e os custos ficam concentrados sobre certas categorias. [...] as políticas majoritárias, são aquelas em que os custos e benefícios são distribuídos pela coletividade (SECCHI, 2014, p. 19).

Numa outra tipologia exibida no livro, Gormley considera o "nível de saliência (capacidade de afetar e chamar a atenção do público em geral) e o nível de complexidade (necessidade de conhecimento especializado para sua formulação e implementação) ”. Assim sendo, “um assunto é saliente quando "afeta um grande número de pessoas de modo significativo” e é complexo quando “levanta questões fatuais que não podem ser respondidas por generalistas ou amadores” (SECCHI, 2014, p. 20).

A seguir, o livro trata acerca da tipologia de Gustafsson, na qual "tem como critério de distinção o conhecimento e a intenção do policymaker” (SECCHI, 2014, p. 21) e considera:

Revista Brasileira de Políticas Públicas e Internacionais, v.2, n.2, Dezembro/2017, pp. 168-175. 
Políticas simbólicas; são aquelas que os policymakers até possuem condições de elaborá-la, mas intimamente não demostram grande interesse em colocá-las em prática [...] As pseudopolíticas; são aquelas em que o policymaker até tem interesse e gostaria de ver sua política funcionando, mas não possui conhecimento para estrutura-la adequadamente [...] Política sem sentido; é aquela elaborada sem conhecimento específico sobre o problema ou sem alternativas de solução para o problema, além de ser vazia de intenções políticas genuínas [...] Política pública real; quando incorporam a intenção de resolver um problema público com o conhecimento para resolvê-lo (SECCHI, 2014, p. 22).

Finalmente é analisada a tipologia de Bozeman e Pandey que consideram que “outra forma de distinguir as políticas públicas de acordo com seus conteúdos e a distinção entre conteúdo técnico e conteúdo político” (SECCHI, 2014, p. 23):

O capítulo três está dedicado à dimensão temporal, e, portanto, a analise das fases do ciclo ou processo de políticas públicas. Secchi (2014) considera que “o processo de elaboração de políticas públicas (policy-making process) também é conhecido como ciclo de políticas públicas (policy cycle). " Assim sendo, as sete fases do processo apontadas pelo autor são: Identificação do problema; Formação da agenda; Formulação de alternativas; Tomada de decisão; Implementação; Avaliação; Extinção (SECCHI, 2014, p. 33).

Na identificação, o problema se considera como "a discrepância entre o status quo e uma situação ideal possível. Um problema público é a diferença entre o que é, e aquilo que se gostaria que fosse a realidade pública” (SECCHI, 2014, p. 34).

O seguinte passo é a formação da agenda, Secchi (2014) cogita que “a agenda é um conjunto de problemas ou temas entendidos como relevantes” (p. 36), assim sendo, o autor disse que basicamente existem dois tipos de agenda: política ou "conjunto de problemas ou temas que a comunidade política percebe como merecedor de intervenção pública”; e formal "também conhecida como agenda institucional, é aquela que elenca os problemas ou temas que o poder público já decidiu enfrentar” (ibidem, p. 36).

Na terceira etapa, no que concerne à construção de alternativas, o autor considera que “é o momento em que são elaborados métodos, programas, estratégias ou ações que poderão alcançar os objetivos estabelecidos. Um mesmo objetivo pode ser alcançado de várias formas, por diversos

Revista Brasileira de Políticas Públicas e Internacionais, v.2, n.2, Dezembro/2017, pp. 168-175. 
ABAD, Alberto. "Políticas Públicas: conceitos, esquemas de análise, casos práticos", de Leonardo Secchi

caminhos” (SECCHI, 2014, p. 37). Assim o policymaker pode utilizar quatro mecanismos para indução de comportamento:

Premiação: influenciar comportamento com estímulos positivos [...] Coerção: influenciar comportamento com estímulos negativos [...] Conscientização: influenciar comportamento por meio da construção e apelo ao senso de dever moral [...] Soluções técnicas: não influenciar comportamento diretamente. Mas sim aplicar soluções práticas que venham a influenciar comportamento de forma direta (SECCHI, 2014, p. 39).

A Tomada de decisão "representa o momento em que os interesses dos atores são equacionados e as intenções (objetivos e métodos) de enfrentamento de um problema público são explicitadas (SECCHI, 2014, p. 40). Assim, surgem os chamados modelos de racionalidade.

No seguinte quesito, relacionado com a implementação da política pública, o autor considera que é importante estudar essa fase para "visualizar, por meio de instrumentos analíticos mais estruturados, os obstáculos e as falhas que costumam acometer essa fase do processo nas diversas áreas de política pública (saúde, educação, habitação, saneamento, políticas de gestão, etc.) ” (p. 45). E além disso, Secchi menciona que "também significa visualizar erros anteriores à tomada de decisão, a fim de detectar problemas mal formulados, objetivos mal traçados, otimismos exagerados” (SECCHI, 2014, p. 45).

Secchi (2014) cita a Sabatier (1986) ao mencionar dois modelos de implementação de políticas públicas:

Modelo top-down; caracterizado pela separação clara entre o momento de tomada de decisão e o de implementação, em fases consecutivas. Esse modelo é baseado na distinção wilsoniana entre "Política e Administração" (WILSON, 1887), no qual os tomadores de decisão (políticos) são separados dos implementadores (administração) (SECCHI, 2014, p. 46).

Modelo bottom-up: caracterizado pela maior liberdade de burocratas e redes de atores em auto organizar e modelar a implementação de políticas públicas (SECCHI, 2014, p. 47).

O seguinte ponto, no ciclo de políticas públicas, refere-se à avaliação, a qual “é o processo de julgamentos deliberados sobre a validade de propostas para a ação pública, bem como, sobre o

Revista Brasileira de Políticas Públicas e Internacionais, v.2, n.2, Dezembro/2017, pp. 168-175. 
ABAD, Alberto. "Políticas Públicas: conceitos, esquemas de análise, casos práticos", de Leonardo Secchi

sucesso ou a falha de projetos que foram colocados em prática” (ANDERSON, 1977, p, 711 apud SECCHI, 2014, p. 49).

A última etapa, ou extinção da política pública pode originar-se, de acordo com Giuliani (2005 apud Secchi, 2014), com base em três causas: o problema que originou a política é percebido como resolvido; os programas, as leis ou as ações que ativavam a política pública são percebidos como ineficazes; ou o problema perdeu importância (SECCHI, 2014, p. 53).

O quarto capítulo destina-se para analisar a dimensão espacial ou das instituições no processo de política pública, apresentando assim a dimensão espacial, onde as políticas públicas acontecem.

Nesse intuito Secchi (2014) comenta que:

De acordo com a escola institucionalista tradicional, instituições são de regras formais, que condicionam o comportamento dos indivíduos. Aplicando esse conceito à área de políticas públicas, as instituições são as regras constitucionais, os estatutos e códigos legais, as políticas públicas passadas e os regimentos internos das arenas onde as políticas públicas são construídas. Instituições nessa acepção são: jurisdições (leis), competências (funções) e as delimitações territoriais (SECCHI, 2014, p. 55).

O quinto capítulo trata dos autores no processo de política pública, que são:

[...] todos aqueles indivíduos, grupos ou organizações que desempenham um papel na arena política. Os atores relevantes em um processo de política pública são aqueles que têm capacidade de influenciar, direta ou indiretamente, o conteúdo e os resultados da política pública. São os atores que conseguem sensibilizar a opinião pública sobre problemas de relevância coletiva. São os atores que têm influência na decisão do que entra ou não na agenda. São eles que estudam e elaboram propostas, tomam decisões e fazem que intenções sejam convertidas em ações (SECCHI, 2014, p. 77).

As categorias dos autores podem ser basicamente divididas em três segundo Moon e Ingraham (1998): políticos, burocratas e sociedade civil:

Cada arena política tem uma configuração de atores peculiar, com prevalência de alguns e ausência de outros. A arena política da área de saúde é ocupada por atores diferentes dos da arena de segurança pública, que por sua parte tem configuração diferente da arena de reformas administrativas (SECCHI, 2014, p 80).

Revista Brasileira de Políticas Públicas e Internacionais, v.2, n.2, Dezembro/2017, pp. 168-175. 
ABAD, Alberto. "Políticas Públicas: conceitos, esquemas de análise, casos práticos", de Leonardo Secchi

Secchi também distingue os modelos de gestão provenientes da administração pública: “o modelo burocrático weberiano, que prega os princípios de legalidade e impessoalidade, e o modelo gerencial, que prega conceitos de eficácia e orientação ao cliente/usuário dos serviços públicos (SECCHI, 2009) ” (SECCHI, 2014, p. 84).

A seguir, Secchi apresenta de maneira sintética os modelos de relação e prevalência e para isso define os seguintes conceitos:

[...] construtos teóricos, testados empiricamente, de como os atores interagem, quais são suas conexões, coalizões e enfrentamentos mais prováveis. Por modelo de prevalência nos referimos a construtos teóricos, também alimentados pela observação prática, de quais atores conseguem fazer valer suas vontades sobre a vontade dos demais atores em um processo de política pública (SECCHI, 2014, p. 94).

O primeiro modelo apresentado por Secchi é o modelo principal agente, onde:

[...] o principal é aquele que contrata uma pessoa ou organização para que ela faça coisas em seu nome. O agente é a pessoa ou organização contratada pelo principal. Usando este modelo para interpretar fenômenos em políticas governamentais, pode-se perceber uma cadeia de relacionamentos (SECCHI, 2014, p. 95).

O segundo modelo apresentado é das redes de políticas públicas, as quais "é uma estrutura de interações, predominantemente informais, entre atores públicos e privados envolvidos na formulação e implementação de políticas públicas”. Assim suas principais características são: interdependência entre os atores que as compõem, liberdade de entrada e saída para seus membros, controle disperso e relações informais e não hierárquicas, e busca de interesses externos aos membros da rede (SECCHI, 2014, p. 97).

Por sua parte, o autor apresenta os modelos elitistas que "consolidaram a visão de que poucos atores (elites) têm a capacidade de determinar o rumo das políticas públicas” (SECCHI, 2014, p. 98). Assim, para

[...] os marxistas estruturalistas, como Althuser e Poulantzas, a elite em um sistema capitalista é representada pelos detentores do capital. Segundo esta corrente, o estado é dominado pelos interesses econômicos capitalistas que o forçam a reproduzir os esquemas de exploração de uma classe (trabalhadores) pelos de outra (capitalistas). As políticas públicas, por consequência, nada mais são que

Revista Brasileira de Políticas Públicas e Internacionais, v.2, n.2, Dezembro/2017, pp. 168-175. 
ABAD, Alberto. "Políticas Públicas: conceitos, esquemas de análise, casos práticos", de Leonardo Secchi

expressões de um estado reprodutor dos interesses do capital (SECCHI, 2014, p. 99).

Para Secchi o modelo pluralista, ao contrário do elitismo "não percebe a predominância de um ator ou conjunto de atores, chegando à conclusão de que todos conseguem influenciar, de alguma maneira, as decisões e os caminhos tomados pela comunidade política” (SECCHI, 2014, p. 99).

O último modelo apresentado pelo autor é o modelo de Triângulos de Ferro, em voga na década de 1960:

[...] relações de apoio entre grupos de interesses, políticos parlamentares e burocratas membros de agências governamentais. Segundo tal esquema, a relação entre esses três grupos de atores é considerada crucial na definição de políticas públicas nacionais (SECCHI, 2014, p. 100).

Finalmente, o sexto capítulo aborda a dimensão comportamental que trata dos estilos de políticas públicas, as quais “constituem-se em procedimentos operacionais padrões de elaborar e implementar políticas” (SECCHI, 2014, p. 103).

Revista Brasileira de Políticas Públicas e Internacionais, v.2, n.2, Dezembro/2017, pp. 168-175. 